\title{
Induction of neutralising antibodies by virus-like particles harbouring surface proteins from highly pathogenic $\mathrm{H5NI}$ and H7N I influenza viruses
}

\author{
Judit Szécsi1 1,2,3, Bertrand Boson 1,2,3, Per Johnsson1,2,3, Pia Dupeyrot- \\ Lacas $^{1,2,3,4}$, Mikhail Matrosovich ${ }^{5}$, Hans-Dieter Klenk ${ }^{5}$, David Klatzmann ${ }^{6}$, \\ Viktor Volchkov ${ }^{1,2,3}$ and François-Loïc Cosset*1,2,3
}

\begin{abstract}
Address: ${ }^{1}$ INSERM, U758, F-69007 Lyon, France, ${ }^{2}$ Ecole Normale Supérieure de Lyon, F-69007 Lyon, France, ${ }^{3}$ IFR128 BioSciences Lyon-Gerland, F-69007 Lyon, France, ${ }^{4}$ Epixis SA, Lyon, F-69007 Lyon, France, ${ }^{5}$ Institut fur Virologie, Universitatsklinikum Giessen und Marburg, D-35033 Marburg, Germany and 'Laboratoire de Biologie et Thérapeutique des Pathologies Immunitaires, CNRS-UMR7087, Université Pierre et Marie Curie, Hôpital Pitié-Salpêtrière, 83 Bd de l'Hôpital, 75013 Paris, France

Email: Judit Szécsi - judit.szecsi@ens-lyon.fr; Bertrand Boson - bboson@ens-lyon.fr; Per Johnsson - per.johnsson@ens-lyon.fr; Pia DupeyrotLacas - Pia.Dupeyrot-Lacas@ens-lyon.fr; Mikhail Matrosovich - Mikhail.Matrosovich@med.uni-marburg.de; Hans-

Dieter Klenk - Klenk@med.uni-marburg.de; David Klatzmann - david.klatzmann@chups.jussieu.fr; Viktor Volchkov - volchkov@cervi-

lyon.inserm.fr; François-Loïc Cosset* - flcosset@ens-lyon.fr

* Corresponding author
\end{abstract}

Published: 03 September 2006

Virology Journal 2006, 3:70 doi:10.1186/1743-422X-3-70

This article is available from: http://www.virologyj.com/content/3/I/70

(C) 2006 Szécsi et al; licensee BioMed Central Ltd.

This is an Open Access article distributed under the terms of the Creative Commons Attribution License (http://creativecommons.org/licenses/by/2.0), which permits unrestricted use, distribution, and reproduction in any medium, provided the original work is properly cited.

\begin{abstract}
Summary
There is an urgent need to develop novel approaches to vaccination against the emerging, highly pathogenic avian influenza viruses. Here, we engineered influenza viral-like particles (Flu-VLPs) derived from retroviral core particles that mimic the properties of the viral surface of two highly pathogenic influenza viruses of either $\mathrm{H} 7 \mathrm{NI}$ or $\mathrm{H} 5 \mathrm{NI}$ antigenic subtype. We demonstrate that, upon recovery of viral RNAs from a field strain, one can easily generate expression vectors that encode the HA, NA and M2 surface proteins of either virus and prepare high-titre Flu-VLPs. We characterise these Flu-VLPs incorporating the HA, NA and M2 proteins and we show that they induce high-titre neutralising antibodies in mice.
\end{abstract}

Influenza virus infects thousands of people each year, causing epidemics with severe mortality [1]. Moreover, there is an increasing concern about a potential influenza pandemic, as highly virulent avian influenza strains are spreading from South-East Asia, with a high risk to cross species-specific barriers [2]. With such a menace, we should be well prepared to prevent excessive mortality, should a virulent pandemic occur.

Vaccination, so far, has been the best manner to protect individuals from influenza infection. Influenza vaccines have been used for ca. 50 years [3]. Current influenza vaccines are mostly inactivated formulations relying on the antigenic activity of the surface glycoproteins of influenza virus: a hemagglutinin (HA) and a neuraminidase (NA) [4]. A major problem, when preparing an influenza vaccine, is the lack of cross-immunity generated against different influenza virus subtypes. This is due to the high mutagenic capacity of influenza virus to generate forms that can escape the immune system. Antigenic shifts and antigenic drifts are evolutionary mechanisms that lead to serologically different influenza virus subtypes or strains 
against which a vaccine is not efficient [5]. Thus, new vaccines need to be prepared during each seasonal influenza epidemic and, importantly, there is no vaccine against the novel, emerging highly pathogenic viruses. Influenza vaccines are generally produced from virus grown in embryonated chicken eggs. This implies that manufacturing a vaccine preparation, from the appearance of a new subtype of influenza virus until the readiness of the vaccine, takes several months [6]. Moreover, one needs to modify the HA of highly virulent influenza strains in order to be able to produce vaccines without killing the embryos. Recently, reverse genetic methods have been used to produce vaccines in cell culture $[6,7]$. Finally, in the event of a pandemic, the vaccine production has to be massive, quick and safe.

Altogether, there is a strong need for developing novel immunogenic formulations that can rapidly be prepared as vaccines against the emerging highly pathogenic avian influenza virus. As a step along this road, here we describe a novel influenza virus immunogen using engineered viral-like particles (Flu-VLPs) that mimic the properties of the viral surface of two highly pathogenic influenza viruses of $\mathrm{H} 7 \mathrm{~N} 1$ and $\mathrm{H} 5 \mathrm{~N} 1$ subtypes.

We used the surface proteins HA, NA and M2 of two highly pathogenic avian influenza viruses: A/Chicken/ FPV/Rostock/1934 (H7N1) [8] and A/Thailand/KAN-1/ 04 (H5N1) $[9,10]$ to generate Flu-VLPs (H7-VLPs and H5VLPs, respectively). The influenza hemagglutinin is responsible for virion attachment to the target cells through recognition and binding to terminal sialic acid groups on membrane-bound proteins of the host cell (reviewed in [11]). The neuraminidase destroys non-functional receptors to which hemagglutinin can bind and thus facilitates virus access to target cells at the early stages of infection and promotes egress of progeny viral particles from infected cells late in infection [12,13]. M2 is a small transmembrane protein with an ion channel activity which regulates the $\mathrm{pH}$ inside the virion during viral entry into cell and protects newly synthesized acid-labile H5 and $\mathrm{H} 7 \mathrm{hemagglutinins}$ during their transport through low $\mathrm{pH}$ cellular compartments (reviewed in $[14,15]$ ). Cloning of expression vectors for HA, NA and M2 from $\mathrm{H} 7 \mathrm{~N} 1$ virus has been described elsewhere $[8,16-19]$. The human virus isolate of H5N1, A/Thailand/KAN-1/04 (H5N1) [9], was kindly provided by Pilaipan Puthavathana at Mahidol University, Bangkok, Thailand. We made one passage of the original seed virus in MDCK cells and isolated viral RNA using the High Pure RNA isolation kit (Roche Molecular Biochemicals, Mannheim, Germany). HA, NA and M2 coding sequences were then amplified from total viral RNA using Superscript Reverse transcriptase and specific primers (sequences are available upon request). PCR products were introduced into a CMV promoter-driven expression plasmid in a manner identical to that used for H7N1 [18].

Flu-VLPs were assembled on replication-defective core particles derived from murine leukaemia virus (MLV). For immunisation purposes, they consisted of empty "core" particles generated by the sole expression of MLV Gag proteins [20], whereas for infectious assays, they comprised MLV GagPol proteins and a recombinant genome encoding the green fluorescent protein (GFP) $[16,19]$. Transduction of this marker gene in 'infected' target cells and expression of GFP in transduced cells is indeed an accurate reflection of the infection steps mediated by the surface glycoproteins of retrovirus-derived VLPs $[17,21,22]$ and, hence, is a convenient way to study cell entry and neutralisation of highly pathogenic viruses in category 2 laboratories [23-25]. We produced Flu-VLPs harbouring at their surface HA, HA and either NA or M2, or all three proteins derived from the H7N1 or H5N1 viruses, by transient expression in $293 \mathrm{~T}$ cells of surface (HA, NA, M2) and internal (Gag, GFP marker genome) viral components. Expression of the different viral proteins in producer cells and their incorporation on sucrose cushion-purified viral particles was characterized by Western blot using specific primary antibodies (Fig. 1A). All proteins were readily expressed in producer cells (not shown). The hemagglutinin, detected as uncleaved $\mathrm{HA}_{0}$ precursor and $\mathrm{HA}_{1} / \mathrm{HA}_{2}$ cleaved mature forms, was incorporated on the surface of the viral particles at high levels for both H7-VLPs and H5VLPs, when expressed together with NA (Fig. 1A). The neuraminidase and $\mathrm{M} 2$ protein were also detected on purified viral particles (Fig. 1A), yet at low levels as compared to their expression in producer cells (data not shown).

The expression of M2 during Flu-VLP production did not influence the incorporation of HA or NA onto the viral particles (Fig. 1A). In contrast, only small amounts of HA proteins were detected on particles when NA was not coexpressed in producer cells, correlating with low quantities of MLV Gag-derived capsid (CA) proteins (Fig. 1A). This was most likely due to a less effective release of VLPs into the cell supernatant in the absence of NA. Indeed treatment of these latter cells with purified neuraminidase from Vibrio cholerae induced efficient release of the viral particles (data not shown). This confirmed the essential role of NA to promote the release virus particles from the cell surface by removing sialic acid receptors from producer cells $[12,26]$.

To estimate the concentration of Flu-VLPs, we determined their 'transduction titres' by adding serial dilutions of viral particle preparations harbouring a GFP marker gene to TE671 human rhabdomyosarcoma cells. The medium was then replaced with normal culture medium and the 


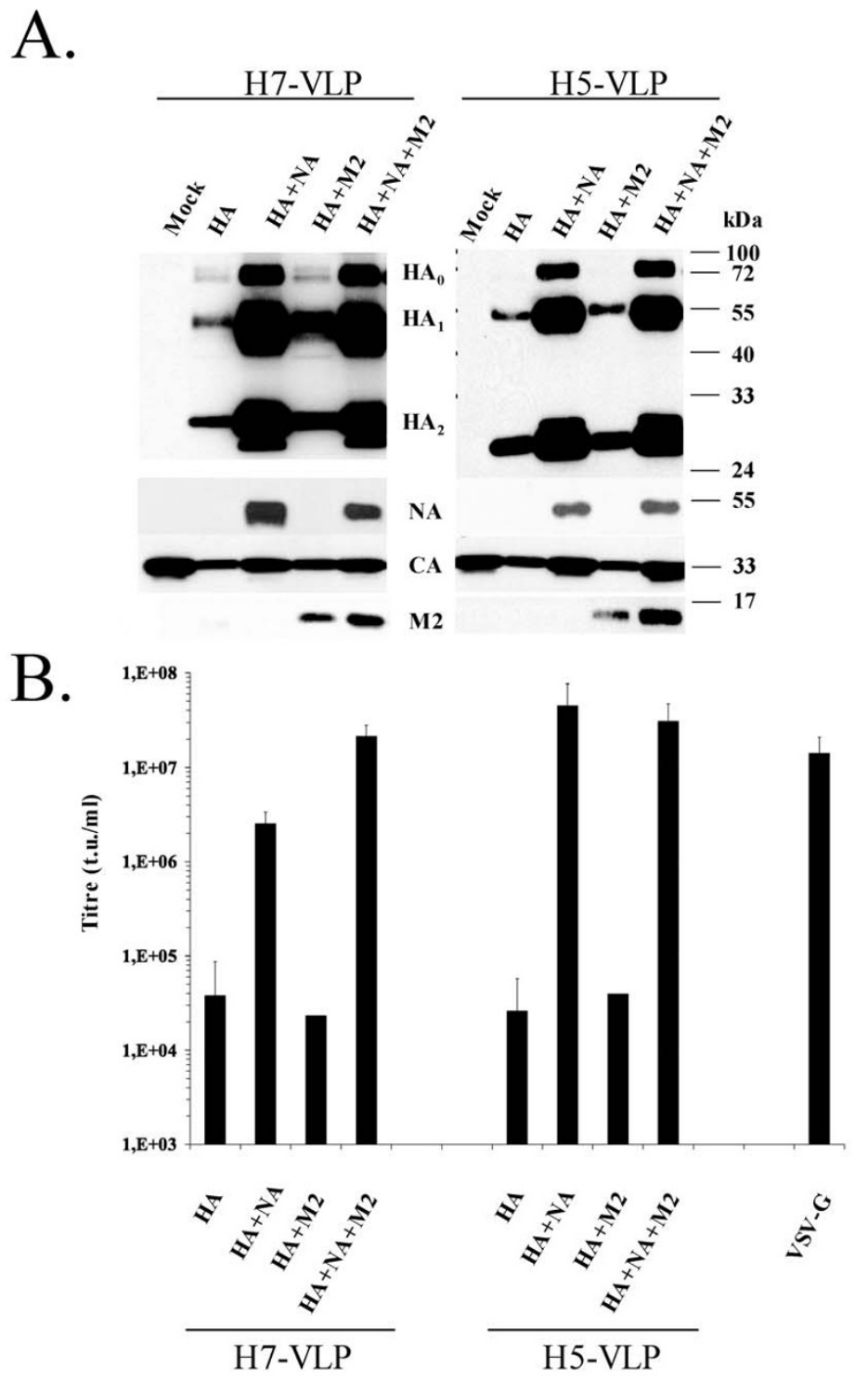

Figure I

Biochemical and functional analysis of Flu-VLPs. A. Incorporation of HA, NA and M2 proteins from H7NI (A/Chicken/ FPV/Rostock/1934) or H5NI (A/Thailand/KAN-I/04) influenza viruses on MLV retroviral core particles, as indicated. Purified VLPs were loaded on SDS-PAGE and incorporation levels of the different proteins were determined by Western Blot analysis using polyclonal sera against $\mathrm{H} 7 \mathrm{NI}-\mathrm{HA}, \mathrm{H} 5 \mathrm{~N} 3-\mathrm{HA}, \mathrm{H} 7 \mathrm{NI}-\mathrm{NA}$ and $\mathrm{M} 2$ proteins. $\mathrm{HA}_{0}$ : HA precursor protein, $\mathrm{HA}$ : $\mathrm{HA}$ surface subunit; $\mathrm{HA}_{2}$ : $\mathrm{HA}$ transmembrane subunit; NA: neuraminidase; $\mathrm{CA}$ : MLV capsid protein. The difference in the molecular weight of $\mathrm{H} 5$ vs. $\mathrm{H} 7 \mathrm{HA}_{2}$, of ca. $3 \mathrm{kDa}$, was due to the presence of an additional glycan for $\mathrm{H} 7 \mathrm{HA}_{2}$. B. Infectious titres obtained with Flu-VLPs incorporating surface proteins from H7NI or H5NI influenza viruses or with VSV-VLPs incorporating the VSV-G of vesicular stomatitis virus (VSV), as indicated. VLP-containing supernatants were used to infect $10^{5}$ TE67I target cells plated in I2-well for $6 \mathrm{hr}$ at $37^{\circ} \mathrm{C}$. The transduction efficiency of GFP, determined as the percentage of GFP-positive cells, was measured by fluorescence-activated cell sorter (FACS) analysis $72 \mathrm{hr}$ after infection, as previously described [22]. The transduction titres, provided as GFP-transducing units (t.u.)/ml, were calculated by using the formula: Titre $=\%$ inf $\times(105 / 100) \times d$, where "d" is the dilution factor of the viral supernatant and "\%inf" is the percentage of GFP-positive cells as determined by FACS analysis using dilutions of the viral supernatant that transduced between $0.1 \%$ and $5 \%$ of GFP-positive cells. Due to the use of a FACS method to monitor transduced cells, the determination of GFP-positive cell below $0.1 \%$, i.e., corresponding to transduction titres below $10^{3}$ t.u./ml in our experimental conditions, could not be accurately be determined. The background levels of transduction were therefore fixed at $10^{3} \mathrm{t} . \mathrm{u} . / \mathrm{ml}$ in all experiments. 
transduction titre was deduced $72 \mathrm{hr}$ later from the percentage of GFP-positive cells measured by fluorescenceactivated cell sorter (FACS) analysis, as previously described [22].

In accordance with biochemical data (Fig. 1A), Flu-VLPs produced in the absence of NA displayed relatively low transduction titres, below $10^{5}$ t.u./ml (Fig. 1B). Consistent with its effect on HA incorporation (Fig. 1A), the presence of NA increased the infectivity by about 100 fold for H7VLPs and 1,000 fold for H5-VLPs, raising transduction titres higher than those obtained with VLPs harbouring VSV-G (VSV-VLPs), one of the most efficient viral surface glycoprotein in such assays [17]. Of note, the infectivity of the Flu-VLPs was specifically and completely abolished by immune sera from animals inoculated with wild type influenza virus (Fig. 2A).

Interestingly, the transduction titres obtained with H7VLPs were about 50 -fold lower than those obtained with H5-VLPs (Fig. 1B). Furthermore, incorporation of M2 onto the Flu-VLPs increased the infectivity of H7-VLPs by about 10 times (Fig. 1B), as reported previously [27], but not that of H5-VLPs, as similar H5 HA incorporation levels were reached irrespective of whether or not M2 was expressed (Fig. 1A). This suggested that H7 HA, but not H5 HA, was sensitive to M2 functions. Consistent with its capacity to regulate the internal $\mathrm{pH}$ of endosomal compartments, the role of M2 during Flu-VLP production is probably to prevent acidification and premature activation of HA protein, an event for which H7N1 virus HA is apparently more sensitive than $\mathrm{HA}$ of $\mathrm{H} 5 \mathrm{~N} 1$ virus strain used in this study.

Altogether, these results indicated that HA, NA and M2 incorporated onto the surface of VLPs are functional as they efficiently mediate cell entry.

We then investigated whether Flu-VLPs harbouring all three viral proteins can induce specific immune responses and neutralising antibodies in mice. For these studies, H7VLPs or H5-VLPs were concentrated and purified by ultracentrifugation [19] before injection in BalbC mice. Control VLPs, incorporating the VSV-G glycoprotein $[17,18]$, were also prepared and injected to mice in parallel. As an attempt to induce cross-neutralising antibodies against different influenza strains, we generated H7-VLPs or H5VLPs treated with a citrate buffer at pH5.3 for 10 minutes. Indeed, at low $\mathrm{pH}$, HA undergoes irreversible conformational changes that are required to induce membrane fusion [28]. Such conformational changes alter the structure and antigenicity of HA $[29,30]$ and may result in exposure of conserved epitopes, hidden in the native HA conformation, that could induce cross-neutralising antibodies that are not raised otherwise, particularly in con- served regions of $\mathrm{HA}_{2}$ [31]. Conformational changes were verified by demonstration of a complete loss of infectivity by low pH-treated particles (data not shown) [28].

About $10^{8}$ particles of H7-VLPs or H5-VLPs, treated or non-treated at low $\mathrm{pH}$, as well as VSV-VLPs particles were repeatedly injected intraperitoneally in 5 week-old female BalbC mice at 2 weeks intervals. The sera were harvested 2 weeks after each injections (harvests S1, S2, S3 and S4) and were decomplemented by heat inactivation at $56^{\circ} \mathrm{C}$ for $1 \mathrm{hr}$. We next determined the neutralising activity of the sera using the Flu-VLPs or the VSV-VLPs harbouring a GFP marker gene. The results of a typical experiment shown in Fig. 2A, are displayed as the \% of neutralisation of the S2 sera compared to the S0 pre-immune sera, i.e., sera harvested before the first inoculation for each mouse, for a 1/100 dilution of these sera. Sera from mice injected with H7-VLPs neutralised specifically H7-VLPs, but neither the H5-VLPs nor the VSV-VLPs and vice-versa. Sera from mice injected with native Flu-VLPs neutralised more efficiently the homologous Flu-VLPs than sera from mice injected with acid pH-denatured Flu-VLPs; yet no crossneutralisation was observed for the latter sera. Consistently, as tested on immunoblots of H7-VLPs vs. H5-VLPs, no cross-reactivity of H7- and H5-VLP sera could be observed for HA. Antibodies against M2 that detected M2 from either influenza virus strain were raised in some immunised mice (Fig. 2B), in agreement with the strong sequence homology between H7 M2 and H5 M2. No cross-reacting NA antibodies could be detected (Fig. 2B), perhaps owing to the relatively inefficient incorporation of this glycoprotein on the Flu-VLPs. Only few other nonspecific protein bands were observed (Fig. 2B), suggesting that the antibody response against Flu-VLPs was specific. To investigate how the neutralising titres increased after repeated immunisations, we determined the titration curves for each serum harvest. The results are shown in Fig. $2 \mathrm{C}$ as the mean neutralisation values from sera of the different groups of mice. The neutralisation curves were similar for both H7 and H5 sera. We found that S1 sera, harvested 2 weeks after the first injection, had significant neutralising activity, with 50\% neutralising activityreached at the $1 / 500$ serum dilution and with an $\mathrm{ID}_{90}$ at the 1/100 dilution. The S2, S3 and S4 sera had much higher neutralising activities, even at high dilutions, with $\mathrm{ID}_{95}$ obtained at the $1 / 2,500$ dilution for the $\mathrm{S} 3$ and/or S4 sera.

Altogether these results indicated that retroviral-derived VLPs incorporating HA, NA and M2 influenza proteins are able to induce antibody production in mice. Moreover, the immune response induced by these particles is rapid and robust, achieving efficient neutralisation only two weeks after the first injection. The produced antibodies are specific, as no cross-reaction between different influenza 
A.

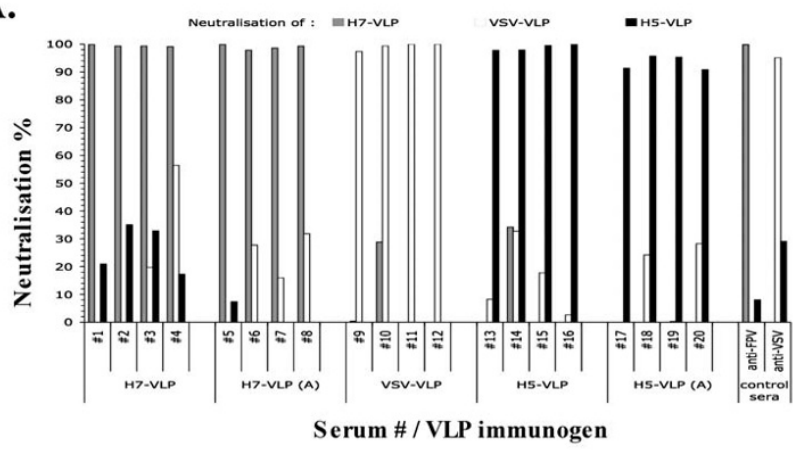

B. H7-VLP immunoblot H5-VLP immunoblot
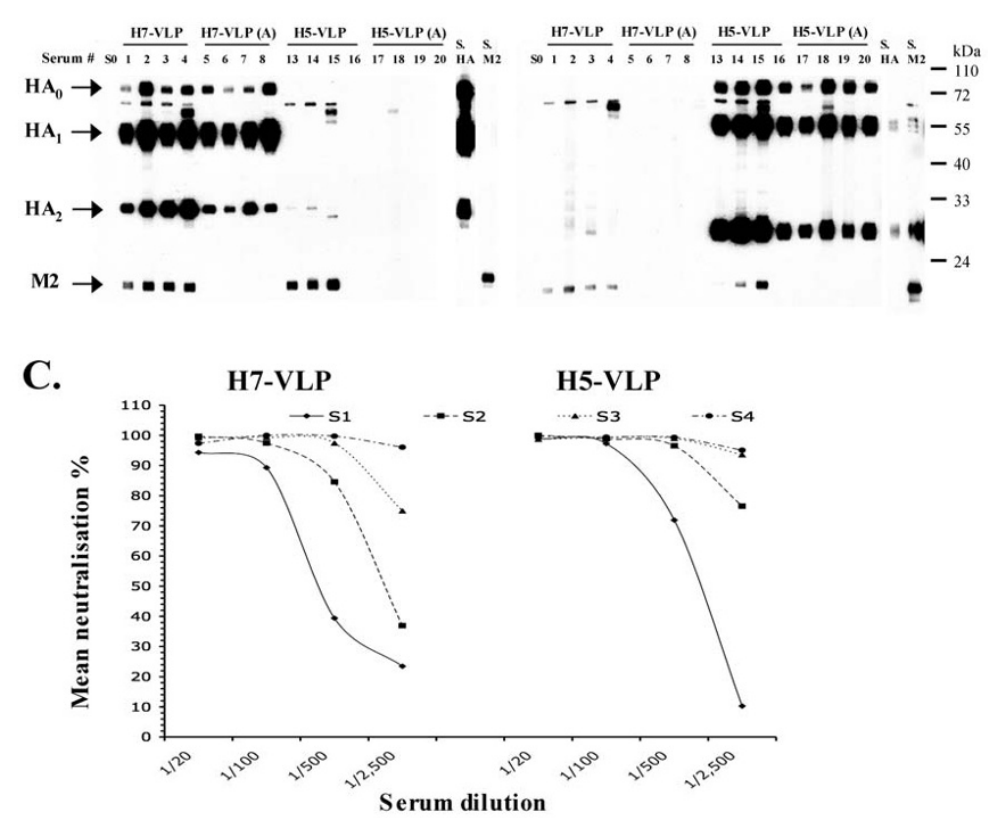

Figure 2

Immunogenicity of Flu-VLPs. A. Neutralising activity of S2 sera from mice immunised with Flu-VLPs incorporating the HA, NA and M2 proteins from H7NI (lanes I-8) or H5NI (lanes I3-20) influenza viruses (H7-VLP and H5-VLP, respectively), or with VSV-VLPs harbouring the VSV-G glycoprotein (lanes 9-12). Some Flu-VLPs were treated at acidic pH5.3 (H7-VLP (A) and H5-VLP (A)) to induce irreversible conformational changes in the HA protein before injection (lanes 5-8 and lanes I3-16 for H7-VLPs and H5-VLPs, respectively). Sera from each mouse were incubated at $37^{\circ} \mathrm{C}$ for 40 min with H7-VLPs, H5-VLPs or VSV-VLPs harbouring a GFP marker gene, as indicated, and then used to infect TE67I target cells. The transduction titres determined in the presence of diluted mouse sera were calculated as described in Fig. I. The results are expressed as the mean percentages (mean $\pm S D ; n=5$ ) of neutralisation of the transduction titres determined with the immune sera relative to titres determine with SO pre-immune sera. Sera or antibodies raised against FPV (fowl plague virus; H7NI influenza virus) and VSV were used as controls in the neutralisation assays (anti-FPV and anti-VSV, respectively). B. Determination of the specificity of antibodies raised in S2 sera from mice immunised with Flu-VLPs by Western blot analysis. H7-VLPs (left) and H5-VLPs (right) were loaded onto SDS-PAGE and transferred to membrane after electrophoresis. Lanes of these membranes were individualised and separately incubated with $\mathrm{S} 2$ sera from immunised mice (see above) at a I/500 serum dilution. S0: pre-immune serum; S. HA; control polyclonal rabbit serum raised H7NI HA; S. M2; control serum raised against H7 M2; $\mathrm{HA}_{0}$ : HA precursor protein; $\mathrm{HA}_{1}$ : $\mathrm{HA}$ surface subunit; $\mathrm{HA}_{2}$ : $\mathrm{HA}$ transmembrane subunit; NA: neuraminidase; M2: M2 matrix protein. $\mathbf{C}$. The neutralising curves of sera from mice immunised with H7-VLPs and H5-VLPs, harvested two weeks after each injection (SI, S2, S3 and S4), were determined for different serum dilutions $(1 / 20,1 / 100,1 / 500$ and $1 / 2,500)$. The results are expressed as the mean percentages (mean $\pm S D ; n=5$ ) of neutralisation of the transduction titres determined with the immune sera relative to titres determine with S0 pre-immune sera. 
strains was observed. Such engineered Flu-VLPs, which can be prepared very rapidly as soon as influenza virus RNAs are isolated, could therefore provide a useful method to obtain in a timely manner a set of efficient immunological reagents such as sera, antibodies and influenza virus-like particles to study neutralisation in low containment laboratories.

Furthermore, we propose that Flu-VLPs that incorporate functional influenza virus surface proteins on defective retroviral core particles could provide a useful immunogenic formulation applicable as a vaccine. Such Flu-VLP can indeed be grown to high titres in mammalian or insect cell cultures to prepare vaccines in vitro [32], or, alternatively, could be secreted in vivo upon inoculation with plasmids [20] or viral vectors [33-35].

\section{Competing interests}

The author(s) declare that they have no competing interests.

\section{Authors' contributions}

JS, DK and FLC conceived the study. JS and FLC coordinated the research efforts and edited the manuscript. $\mathrm{BB}$, PJ, and MM contributed to parts of the experimental work. MM, HDK, DK and VV provided guidance and analysed the data. All authors have read and approved the manuscript.

\section{Acknowledgements}

We thank Dr P. Puthavathana (Mahidol University, Bangkok, Thailand) for providing $\mathrm{H} 5 \mathrm{NI}$ influenza virus. We thank Drs W. Garten, R.G. Webster and $A$. Hay for providing antibodies and sera against $\mathrm{H} 7 \mathrm{NI}$ and $\mathrm{H} 5 \mathrm{~N} 3$ influenza virus surface proteins. We thank the personals from the animal facility "PBES" of the Ecole Normale Supérieure de Lyon.

This work was supported by the European Community (contract LSHBCT-2004-005246 "COMPUVAC"), the Région Rhône-Alpes (FITT 2005) and the Agence Nationale pour la Recherche (ANR "MIME").

\section{References}

I. Nicholson KG, Wood JM, Zambon M: Influenza. Lancet 2003, 362: 1733-1745.

2. Webby RJ, Webster RG: Are we ready for pandemic influenza? Science 2003, 302:1519-1522.

3. Francis TJ: Vaccination against influenza. Bull World Health Organ 1953, 8:725-741.

4. Hilleman MR: Realities and enigmas of human viral influenza: pathogenesis, epidemiology and control. Vaccine 2002, 20:3068-3087.

5. Tamura S, Tanimoto T, Kurata T: Mechanisms of broad crossprotection provided by influenza virus infection and their application to vaccines. Jpn J Infect Dis 2005, 58:195-207.

6. Check E: Avian flu special: is this our best shot? Nature 2005, 435:404-406.

7. Hoffmann E, Krauss S, Perez D, Webby R, Webster RG: Eight-plasmid system for rapid generation of influenza virus vaccines. Vaccine 2002, 20:3165-3170.

8. Ohuchi M, Cramer A, Vey M, Ohuchi R, Garten W, Klenk HD: Rescue of vector expressed fowl plague virus hemagglutinin in biologically active form by acidotropic agents and coexpressed M2 protein. J Virol 1994, 68:920-926.
9. Puthavathana P, Auewarakul P, Charoenying PC, Sangsiriwut $K$ Pooruk P, Boonnak K, Khanyok R, Thawachsupa P, Kijphati R, Sawanpanyalert P: Molecular characterization of the complete genome of human influenza $\mathrm{H} 5 \mathrm{NI}$ virus isolates from Thailand. J Gen Virol 2005, 86:423-433.

10. Amonsin A, Payungporn S, Theamboonlers A, Thanawongnuwech R, Suradhat S, Pariyothorn N, Tantilertcharoen R, Damrongwantanapokin S, Buranathai $C$, Chaisingh A, Songserm T, Poovorawan $Y$ : Genetic characterization of $\mathrm{H} 5 \mathrm{NI}$ influenza $A$ viruses isolated from zoo tigers in Thailand. Virology 2006, 344:480-49I.

II. Skehel Jj, Wiley DC: Receptor binding and membrane fusion in virus entry: the influenza hemagglutinin. Annu Rev Biochem 2000, 69:53I-569.

12. Bucher $D$, Palese $P$ : The biologically active proteins of influenza virus: neuraminidase. In The influenza viruses and influenza Edited by: Kilbourne ED. New York, Academic Press; 1975:83-I23.

13. Matrosovich MN, Matrosovich TY, Gray T, Roberts NA, Klenk HD: Neuraminidase is important for the initiation of influenza virus infection in human airway epithelium. J Virol 2004, 78: | 2665- 12667

14. Lamb RA, Holsinger LJ, Pinto LH: The influenza A virus M2 ion channel protein and its role in the influenza virus life cycle. In Cellular receptors of animal viruses Edited by: Wimmer E. Cold Spring Harbor, Cold Spring Harbor Laboratory; 1994:303-321.

15. Hay AJ: The action of adamantanamines against influenza $A$ viruses: inhibition of the M2 ion channel protein. Semin Virol 1992, 3:21-30.

16. Hatziioannou T, Valsesia-Wittmann S, Russell SJ, Cosset FL: Incorporation of fowl plague virus hemagglutinin into murine leukemia virus particles and analysis of the infectivity of the pseudotyped retroviruses. / Virol 1998, 72:53|3-53I7.

17. Sandrin V, Boson B, Salmon P, Gay W, Nègre $D$, LeGrand R, Trono $D$, Cosset FL: Lentiviral vectors pseudotyped with a modified RDII4 envelope glycoprotein show increased stability in sera and augmented transduction of primary lymphocytes and CD34+ cells derived from human and non-human primates. Blood 2002, 100:823-832.

18. Sandrin V, Cosset FL: Intracellular versus cell surface assembly of retroviral pseudotypes is determined by the cellular localization of the viral glycoprotein, its capacity to interact with Gag, and the expression of the Nef protein. J Biol Chem 2006, 28I:528-542.

19. Szecsi J, Drury R, Josserand V, Grange MP, Boson B, Hartl I, Schneider R, Buchholz C, Coll JL, Russell SJ, Cosset FL, Verhoeyen E: Targeted retroviral vectors displaying a cleavage site-engineered hemagglutinin (HA) through HA-protease interactions. Mol Ther 2006, in press:

20. Bellier B, Dalba C, Clerc B, Desjardins D, Drury R, Cosset FL, Collins $M$, Klatzmann D: DNA vaccines encoding retrovirus-based virus-like particles induce efficient immune responses without adjuvant. Vaccine 2006, 24:2643-2655.

21. Bartosch B, Vitelli A, Granier C, Goujon C, Dubuisson J, Pascale S, Scarselli E, Cortese R, Nicosia A, Cosset FL: Cell entry of hepatitis $C$ virus requires a set of co-receptors that include the CD8 I tetraspanin and the SR-BI scavenger receptor. J Biol Chem 2003, 278:4I624-4I630.

22. Negre D, Mangeot PE, Duisit G, Blanchard S, Vidalain PO, Leissner P, Winter AJ, Rabourdin-Combe C, Mehtali M, Moullier P, Darlix JL, Cosset FL: Characterization of novel safe lentiviral vectors derived from simian immunodeficiency virus (SIVmac25I) that efficiently transduce mature human dendritic cells. Gene Ther 2000, 7:1613-1623.

23. Bartosch B, Dubuisson J, Cosset FL: Infectious hepatitis C virus pseudo-particles containing functional EI-E2 envelope protein complexes. J Exp Med 2003, 197:633-642.

24. Bartosch B, Bukh J, Meunier JC, Granier C, Engle RE, Blackwelder WC, Emerson SU, Cosset FL, Purcell RH: In vitro assay for neutralizing antibody to hepatitis $C$ virus: evidence for broadly conserved neutralization epitopes. Proc Natl Acad Sci U S A 2003 , 100:14199-14204.

25. Lavillette D, Morice Y, Germanidis G, Donot P, Soulier A, Pagkalos E, Sakellariou G, Intrator L, Bartosch B, Pawlotsky JM, Cosset FL: Human serum facilitates hepatitis $C$ virus infection, and neutralizing responses inversely correlate with viral replication kinetics at the acute phase of hepatitis $\mathbf{C}$ virus infection. Virol 2005, 79:6023-6034. 
26. Bosch V, Kramer B, Pfeiffer T, Starck L, Steinhauer DA: Inhibition of release of lentivirus particles with incorporated human influenza virus haemagglutinin by binding to sialic acid-containing cellular receptors. J Gen Virol 200I, 82:2485-2494.

27. McKay T, Patel M, Pickles RJ, Johnson LG, Olsen JC: Influenza M2 envelope protein augments avian influenza hemagglutinin pseudotyping of lentiviral vectors. Gene Ther 2006, I3:7| 5-724.

28. Skehel JJ, Bayley PM, Brown EB, Martin SR, Waterfield MD, White JM, Wilson IA, Wiley DC: Changes in the conformation of influenza virus hemagglutinin at the $\mathrm{pH}$ optimum of virus-mediated membrane fusion. Proc Natl Acad Sci U S A 1982, 79:968-972.

29. Graves PN, Schulman JL, Young JF, Palese P: Preparation of influenza virus subviral particles lacking the HAI subunit of hemagglutinin: unmasking of cross-reactive HA2 determinants. Virology 1983, I26:106-II6.

30. Sagawa $H$, Ohshima A, Kato I, Okuno $Y$, Isegawa $Y$ : The immunological activity of a deletion mutant of influenza virus haemagglutinin lacking the globular region. J Gen Virol 1996, 77 ( Pt 7): | 483-I 487.

31. Okuno $Y$, Isegawa $Y$, Sasao $F$, Ueda S: A common neutralizing epitope conserved between the hemagglutinins of influenza A virus $\mathrm{HI}$ and $\mathbf{H 2}$ strains. J Virol 1993, 67:2552-2558.

32. Yao Q, Kuhlmann FM, Eller R, Compans RW, Chen C: Production and characterization of simian--human immunodeficiency virus-like particles. AIDS Res Hum Retroviruses 2000, 16:227-236.

33. Duisit G, Salvetti A, Moullier P, Cosset FL: Functional characterization of adenoviral/retroviral chimeric vectors and their use for efficient screening of retroviral producer cell lines. Human Gene Therapy 1999, I0:189-200.

34. Roberts ML, Wells DJ, Graham IR, Fabb SA, Hill VJ, Duisit G, Yuasa K, Takeda S, Cosset FL, Dickson G: Stable micro-dystrophin gene transfer using an integrating adeno-retroviral hybrid vector ameliorates the dystrophic pathology in $\mathrm{mdx}$ mouse muscle. Hum Mol Genet 2003, I I: 1719-1730.

35. Savard N, Cosset FL, Epstein AL: Use of defective HSV-I vectors harbouring gag, pol, and env genes to rescue defective retrovirus vectors. J Virol |997, 7 I:4 I I I-4 I I 7 .

Publish with Bio Med Central and every scientist can read your work free of charge

"BioMed Central will be the most significant development for disseminating the results of biomedical research in our lifetime. "

Sir Paul Nurse, Cancer Research UK

Your research papers will be:

- available free of charge to the entire biomedical community

- peer reviewed and published immediately upon acceptance

- cited in PubMed and archived on PubMed Central

- yours - you keep the copyright
BiolMedcentral 